Revista Brasileira de Farmacognosia Brazilian Journal of Pharmacognosy 21(2): 296-304, Mar./Apr. 2011

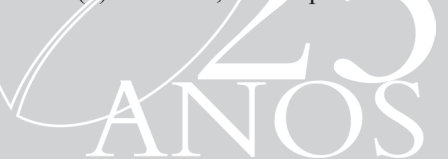

Article

Received 8 Jan 2011

Accepted 28 Jan 2011

Available online 13 May 2011

Keywords:

agaro-oligosaccharides

carra-oligosaccharides

partial acid hydrolysis

3,6-anhydro-galactose

agarose

kappa-carrageenan

ISSN 0102-695X

doi: $10.1590 / \mathrm{S} 0102-695 \mathrm{X} 2011005000080$

\section{Production of agaro- and carra- oligosaccharides by partial acid hydrolysis of galactans}

\author{
Diogo R. B. Ducatti, ${ }^{1}$ Franciely G. Colodi, ${ }^{1}$ Alan G. Gonçalves, ${ }^{2}$ \\ M. Eugênia R. Duarte, ${ }^{1}$ Miguel D. Noseda ${ }^{*}$,
}

${ }^{1}$ Departamento de Bioquímica e Biologia Molecular, Universidade Federal do Paraná, Brazil,

${ }^{2}$ Departamento de Farmácia, Universidade Federal do Paraná, Brazil.

\begin{abstract}
Agaro- and carra-oligosaccharides were produced by partial acid hydrolysis of commercial agarose and kappa-carrageenan. Di- and tetrasaccharides were purified by gel filtration chromatography and characterized by NMR (1D and 2D) spectroscopy and ESIMS. The following oligosaccharides were obtained: agarobiose, agarotetraose, kappa-carrabiose and kappa-carratetraose. Agarobiose and agarotetraose were used as standards to develop a high performance size exclusion chromatography (HPSEC) method which was utilized to study the hydrolysis rate of agarose and oligosaccharide production. Six hours of hydrolysis (0.1 M TFA, 65 ${ }^{\circ} \mathrm{C}$ ) produced mainly di- and tetrasaccharides. The methodology for oligosaccharide production and evaluation developed in the present work shows good potential for the production of bioactive oligosaccharides.
\end{abstract}

\section{Introduction}

Red seaweeds produce linear galactans as the principal constituent of the extracellular matrix. Chemically, these polymers consist of alternating $(1 \rightarrow 3)$-linked $\beta$-D-galactopyranose and $(1 \rightarrow 4)$-linked a-galactopyranose units. Frequently, the 4-linked units are in the 3,6-anhydro form. These polymers are classified according to the stereochemistry of the 4-linked units into agarans (L-enantiomer) and carrageenans (D-enantiomer) (Painter, 1983; Craigie, 1990). Recently, a third group, denominated $\mathrm{D} / \mathrm{L}$-hybrids and containing $\mathrm{D}$ and $\mathrm{L}$ enantiomers of the $\alpha$-Galp units (Zibetti et al., 2005; Zibetti et al., 2009) has emerged. Agarans and carrageenans can present complex substitution patterns due to the presence of sulfate, methyl, 4,6-O-(1'carboxyethylidene) and glycosyl groups (Craigie, 1990).

Galactan oligosaccharides can be obtained through partial acid (Yu et al., 2002; Gonçalves et al., 2010; Ciancia et al., 2005) or enzymatic hydrolysis (Guibet et al., 2006; Young et al., 1978; Rochas et al., 1994). Usually, the partial acid hydrolysis methods (Figure 1) promote the specific cleavage of 3,6-anhydro$\alpha$-galactosidic bonds to produce the reducing di- or tetrasaccharides $\mathbf{2}$ and $\mathbf{4}$, containing the unusual anhydro galactose in hydrated aldehyde form as the terminal unit.
These oligosaccharides can be isolated and characterized (Miller et al., 1982; Fatema et al., 2010) and even used as starting materials to synthesize carbohydrate building blocks (Ducatti et al., 2009). However, due to the instability of 3,6-anhydro-galactose units to harsh acidic conditions, partial hydrolysis with strong and concentrated acids can also produce the reducing trisaccharide 3 containing galactose as the terminal unit (Yang et al., 2009). A good alternative for preserving the anhydro units is the addition of reducing (Usov \& Elashvili, 1991; Gonçalves et al., 2002) or oxidizing (Penman \& Rees, 1973) agents during the hydrolysis step to produce alditol or aldonic oligosaccharides, respectively.

Galactan oligosaccharides and their derivatives can exhibit significant antioxidant (Chen \& Yan, 2005), antitumoral (Haijin et al., 2003) and antiangiogenic (Chen et al., 2007) activities. In particular, oligosaccharides and compounds containing the reducing 3,6-anhydroL-galactose unit, such as agarobiose, agarotetraose and agarohexaose can suppress nitric oxide, prostaglandin E2 and pro-inflammatory cytokine production in vitro (Enoki et al., 2010; Kobayashi et al., 2003). The presence of the anhydro unit at the reducing terminal end appears to play a crucial role in these activities.

Due to the potential applicability of 
oligosaccharides in the pharmaceutical and food industries, production protocols (Enoki et al., 2007) have been developed. In addition, chromatographic methods are utilized to control the hydrolysis process (Chen et al., 2004; Kazlowski et al., 2008), being useful for monitoring bioactive oligosaccharide production.

In this paper we describe the production and characterization of agaro- and carra-oligosaccharides via the partial acid hydrolysis of commercial agarose and kappa-carrageenan. Agarobiose and agarotetraose, purified from agarose, were used as standards to evaluate the hydrolytic process by HPSEC.


Partial acid hydrolysis

$\downarrow$<smiles>OC(O)C1OC2OC(C(O)C(O)C2O)C1O</smiles>

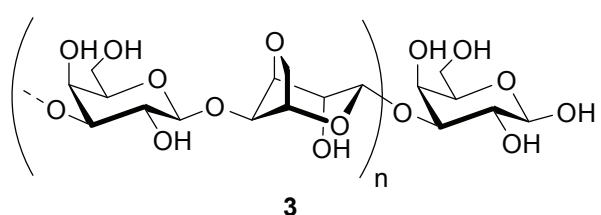

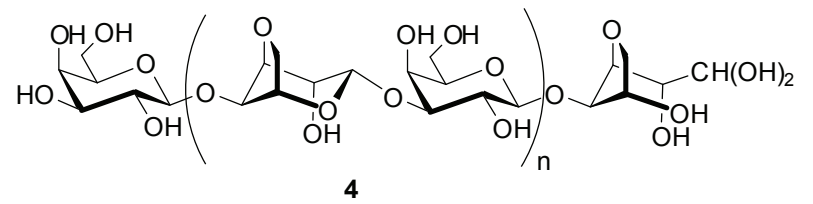

Figure 1. Production of reducing agaro-oligosaccharides through partial acid hydrolysis of agarose.

\section{Materials and Methods}

\section{Chemical and reagents}

Sample 1 corresponded to a commercial agar purchased from Vetec Química (Rio de Janeiro, RJ, Brazil), sample 2 was a commercial agarose purchased from Sigma-Aldrich (St. Louis, MO, USA) and sample 3 was a low melting point agarose purchased from Invitrogen (Carlsbad, CA, USA). Kappa-carrageenan
(KWS) was obtained as previously described (Gonçalves et al., 2005). Trifluoracetic acid, sulfuric acid, and phenol were high purity reagents from Merck. MilliQ Water with a specific resistance higher than $18.2 \mathrm{M} \Omega . \mathrm{cm}$ was utilized for HPLC analysis.

\section{Preparation of agarobiose and agarotetraose}

Sample 1 (150 mg) was first dissolved in hot $\left(\sim 90{ }^{\circ} \mathrm{C}\right) \mathrm{H}_{2} \mathrm{O}(13.5 \mathrm{~mL})$ and then $1 \mathrm{M}$ TFA solution $(1.5$ $\mathrm{mL})$ was added in one portion. The resulting mixture was heated at $65{ }^{\circ} \mathrm{C}$ for $2 \mathrm{~h}$, cooled to room temperature, diluted with $\mathrm{H}_{2} \mathrm{O}(15 \mathrm{~mL})$, and then concentrated under vacuum. The resulting residue was coevaporated with toluene three times to give a syrup. This material was dissolved in $\mathrm{H}_{2} \mathrm{O}(2 \mathrm{~mL})$ and applied on a Bio-Gel P2 column $(70 \times 1.5 \mathrm{~cm})$. Oligosaccharide detection was performed by the phenol-sulfuric acid method (Dubois et al., 1956) and TLC. The TLC was carried out on silica gel 60 (2:2:1 BuOH-AcOH-H2O) with detection by charring with $0.5 \%$ orcinol in EtOH- $\mathrm{H}_{2} \mathrm{SO}_{4}(20: 1)$. The fractions $\mathrm{AA}$ and $\mathrm{AB}$ were concentrated and freeze-dried to give agarobiose $(15 \mathrm{mg})$ and agarotetraose $(13 \mathrm{mg})$, respectively.

\section{Preparation of kappa-carrabiose and kappa- carratetraose}

KWS (150 mg) was first dissolved in hot $(\sim 90$ $\left.{ }^{\circ} \mathrm{C}\right) \mathrm{H}_{2} \mathrm{O}(13.5 \mathrm{~mL})$ and then $1 \mathrm{M}$ TFA solution $(1.5 \mathrm{~mL})$ was added in one portion. The resulting mixture was heated at $65{ }^{\circ} \mathrm{C}$ for $3 \mathrm{~h}$, cooled to room temperature, diluted with $\mathrm{H}_{2} \mathrm{O}(15 \mathrm{~mL})$, and then concentrated under vacuum. The resulting residue was coevaporated with toluene three times to give a syrup. This material was dissolved in $\mathrm{H}_{2} \mathrm{O}(2 \mathrm{~mL})$ and applied on a Sephadex G-25 column $(100 \times 1.5 \mathrm{~cm})$. Oligosaccharide detection was performed as described for agarobiose preparation. The fractions KA and KB were concentrated and freeze-dried to give kappa-carrabiose (31 mg) and kappa-carratetraose (12 mg), respectively.

Production rate of agarobiose and agarotetraose from agarose by HPSEC analysis

Samples of commercial agar $1(10 \mathrm{mg})$ were first dissolved in TFA $0.1 \mathrm{M}$. These mixtures were hydrolyzed at $65{ }^{\circ} \mathrm{C}$ for $1,2,4,6$ and $8 \mathrm{~h}(\mathrm{n}=3$ for each time). After hydrolysis, the solutions were concentrated and freezedried. The resulting hydrolysates $(1 \mathrm{mg})$ were diluted in ultrapure $\mathrm{H}_{2} \mathrm{O}(1 \mathrm{~mL})$ and analyzed by HPSEC. The chromatographies were performed with a Shimadzu equipment using a RI detector operating at $40{ }^{\circ} \mathrm{C}$. The chromatographic separation was achieved with an Ultrahydrogel (Waters) $120(7.8 \times 300 \mathrm{~mm})$ column. Elution 
was carried out with ultrapure water at $30^{\circ} \mathrm{C}$ with a flow rate of $0.4 \mathrm{~mL} \cdot \mathrm{min}^{-1}$. Samples were injected manually with a Rheodyne $7725 \mathrm{i}$ injector (50 $\mu \mathrm{L}$ sample loop). Calibration curves were obtained by injecting increasing concentrations $\left(0.25\right.$ to $\left.2.0 \mathrm{mg} \cdot \mathrm{mL}^{-1}\right)$ of agarobiose and agarotetraose ( $\mathrm{n}=3$ for each concentration).

Monosaccharide composition analysis of the galactans by gas chromatography coupled to mass spectrometry (GC-MS)

Monosaccharide compositions of polysaccharide samples were performed by reductive hydrolysis (Stevenson \& Furneaux, 1991). GC-MS analyses were carried out with a Varian 3800 chromatograph equipped with a fused-silica capillary column $(30 \mathrm{~m}$ x $0.25 \mathrm{~mm})$ coated with DB-225MS (Durabond). The chromatograph was programmed to run at $50^{\circ} \mathrm{C}$ for $1 \mathrm{~min}$, then $50-215^{\circ} \mathrm{C}$ at $40{ }^{\circ} \mathrm{C} \cdot \mathrm{min}^{-1}$, using helium as carrier gas at $1 \mathrm{~mL} \cdot \mathrm{min}^{-1}$.

\section{Nuclear magnetic resonance (NMR) spectroscopy}

1D- and 2D-NMR spectra were acquired on a Bruker Advance DRX 400 spectrometer equipped with a $5 \mathrm{~mm}$ wide bore probe, operating at $400 \mathrm{MHz}$ for ${ }^{1} \mathrm{H}$ and $100 \mathrm{MHz}$ for ${ }^{13} \mathrm{C}$. Samples were exchanged with deuterium by repeated evaporations in $\mathrm{D}_{2} \mathrm{O}$. Analyses were performed in $\mathrm{D}_{2} \mathrm{O}$ at $30^{\circ} \mathrm{C}$ for oligosaccharides and $70{ }^{\circ} \mathrm{C}$ for polysaccharides. The spectra were internally referenced using acetone $\left(\delta=2.224 \mathrm{ppm}\right.$ for ${ }^{1} \mathrm{H}$ and $\delta=30.20 \mathrm{ppm}$ for ${ }^{13} \mathrm{C}$ ).

\section{Electrospray-ionization mass spectrometry (ESI-MS)}

The ESIMS equipment used was a Micromass Quattro LC-MS/MS triple quadrupole mass spectrometer. Data acquisition and processing were performed using Maslynx 3.5 software. Mass spectrometry was carried out in the negative and positive-ion modes. Samples (0.125 mg. $\left.\mathrm{mL}^{-1}\right)$ were injected in a 70:30 Acetonitrile/ water mixture by a syringe pump (KD Scientific Inc.) flowing at $60 \mu \mathrm{L} \cdot \mathrm{min}^{-1}$. ESI conditions were as follows: $\mathrm{N} 2$ was used as nebuliser $\left(87{\left.\mathrm{~L} . \mathrm{h}^{-1}\right)}\right.$ and desolvation gas $\left(429{\mathrm{~L} . \mathrm{h}^{-1}}^{-}\right.$). The source was operated at $80{ }^{\circ} \mathrm{C}$ with a desolvation temperature of $130{ }^{\circ} \mathrm{C}$. The electrospray capillary voltage in the negative-ion mode was $2.79 \mathrm{kV}$ and the cone voltage was $71 \mathrm{~V}$. In the positive-ion mode, the capillary voltage was $1.98 \mathrm{kV}$ and cone voltage was $171 \mathrm{~V}$. The RF lens was set at 0.30 . The mass scan range was 2-1500 u, for 1 min total scan time, with $3 \mathrm{~s}$ scan time and $0.1 \mathrm{~s}$ interscan time.

\section{Results and Discussion}

Production of agarobiose and agarotetraose from agarose

We analyzed the composition of three different commercial samples of agarose by NMR and GC-MS techniques. The monosaccharide compositions of sample 1 and 2 were similar, with galactose and 3,6-anhydrogalactose as the principal constituents (Table 1). Small amounts of 2-O-methyl-3,6-anhydro-galactose and 6-Omethyl-galactose were also observed and the signals of the methyl protons of these units were assigned at 3.51 and 3.42 ppm, respectively, in the ${ }^{1} \mathrm{H}-\mathrm{NMR}$ spectra (Figure 2) (Mazumder et al., 2002). Sample 3 is a low melting point agarose with a lower 3,6-anhydro-galactose content than samples 1 and 2 and a high amount of natural methylated sugars. The ${ }^{13} \mathrm{C}-\mathrm{NMR}$ spectra of all samples showed a resonance at $97.8 \mathrm{ppm}$, which was assigned to $\mathrm{C}-1$ of 3,6anhydro- $\alpha$-L-galactopyranose. The signal corresponding to $\mathrm{C}-1$ of $2-O$-methyl-3,6-anhydro- $\alpha$-L-galactopyranose was observed at $98.4 \mathrm{ppm}$ for sample 3 (Figure 2). The NMR and GC-MS analyses of samples 1 and 2 were similar, indicating that both samples are good sources of agarose with a high degree of purity.

Table 1. Monosaccharide composition ${ }^{\mathrm{a}}$ of commercial agarose samples (1-3) and kappa-carrageenan (KWS).

\begin{tabular}{cccccc}
\hline Samples $^{\mathrm{b}}$ & \multicolumn{5}{c}{ Monosaccharide $(\mathrm{mol} \%)^{\mathrm{c}}$} \\
\cline { 2 - 6 } & Gal & 3,6-AnGal & 2Me-AnGal & 6Me-Gal & 2Me-Gal \\
\hline 1 & 57.0 & 38.5 & 2.2 & 2.1 & 0.3 \\
2 & 54.5 & 42.0 & 2.2 & 1.4 & 0 \\
3 & 49.1 & 29.6 & 9.1 & 4.9 & 7.3 \\
KWS & 44.2 & 50.4 & 0 & 4.7 & 0.7 \\
\hline
\end{tabular}

${ }^{a}$ Compositional analyses determined after total reductive hydrolysis. ${ }^{\mathrm{b}}$ Samples are defined in the Material and Methods section. ${ }^{\mathrm{C}} \mathrm{Gal}$ corresponds to galactosyl units; 3,6-AnGal to 3,6-anhydro-galactosyl units; $2 \mathrm{Me}-\mathrm{AnGal}$ to $2-O$-methyl-3,6-anhydro-galactosyl units; $6 \mathrm{Me}-$ $\mathrm{Gal}$ to 6 -O-methyl-galactosyl units; $2 \mathrm{Me}-\mathrm{Gal}$ to 2 -O-methyl-galactosyl units.

The instability of 3,6-anhydro-galactose residues under acidic conditions has been known since the first structural studies on carrageenans and agarans (O'Neill, 1955; Araki \& Hirase, 1953). Stevenson \& Furneaux (1991) showed that the anhydro units can resist mildly acidic conditions and then be quantified, after derivatization, by GLC. Thus, we submitted agarose (sample 1) to partial acid hydrolysis $\left(0.1 \mathrm{M} \mathrm{TFA}, 65^{\circ} \mathrm{C}, 2 \mathrm{~h}\right)$ to promote the cleavage of 3,6-anhydro-galactosidic linkages. The oligosaccharide mixture was purified on a Bio-Gel P2 column, yielding two distinct fractions, $\mathrm{AA}(10 \%)$ and $\mathrm{AB}(9 \%)$.

${ }^{13} \mathrm{C}-\mathrm{NMR}$ analysis of the fraction AA (Figure $3 \mathrm{a}$ ) showed a spectrum characteristic of a disaccharide with two signals in the anomeric region. The assignments for agarobiose 2 (Table 2 and Figure 1) are in agreement with those previously reported (Miller et al., 1982). Reducing oligosaccharides with 3,6-anhydro-galactose as the terminal unit have a simple ${ }^{13} \mathrm{C}$ NMR spectrum because the 
reducing end does not present mutarotation. Indeed, the typical signal of C-1 of 3,6-anhydro-galactose in the hydrated aldehyde form was observed at $89.9 \mathrm{ppm}$. ESIMS analysis in the positive-ion mode confirmed the structure of 2 (data not shown). Two principal peaks corresponding to the aldehyde form $\left([\mathrm{M}+\mathrm{Na}]^{+}\right.$at $\left.m / z 347\right)$ and the hydrated aldehyde form $\left(\left[\mathrm{M}+\mathrm{H}_{2} \mathrm{O}+\mathrm{Na}\right]^{+}\right.$at $\left.m / z 365\right)$ were observed.
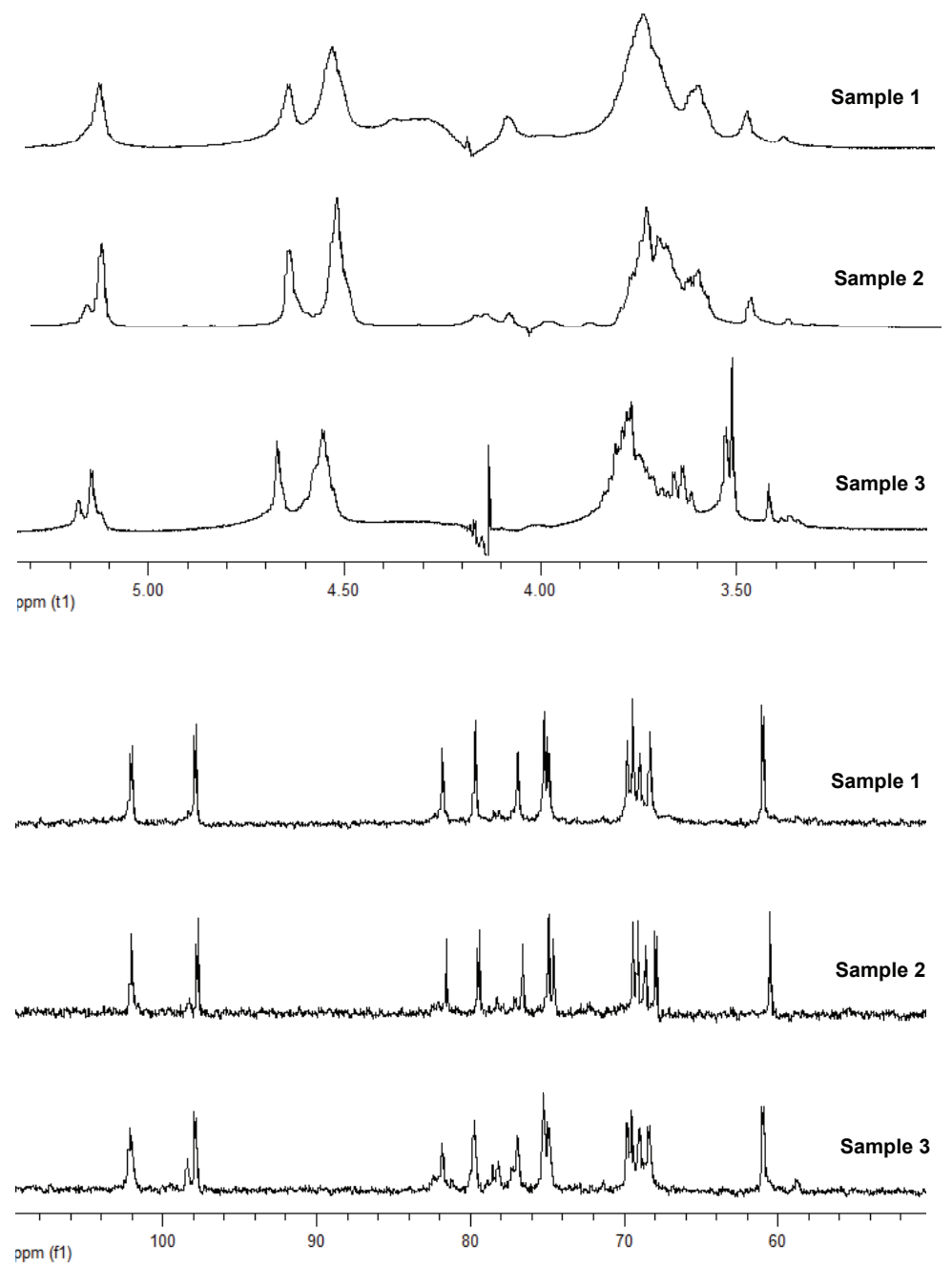

Figure 2. ${ }^{1} \mathrm{H}-$ and ${ }^{13} \mathrm{C}-\mathrm{NMR}$ spectra of commercial agarose samples.
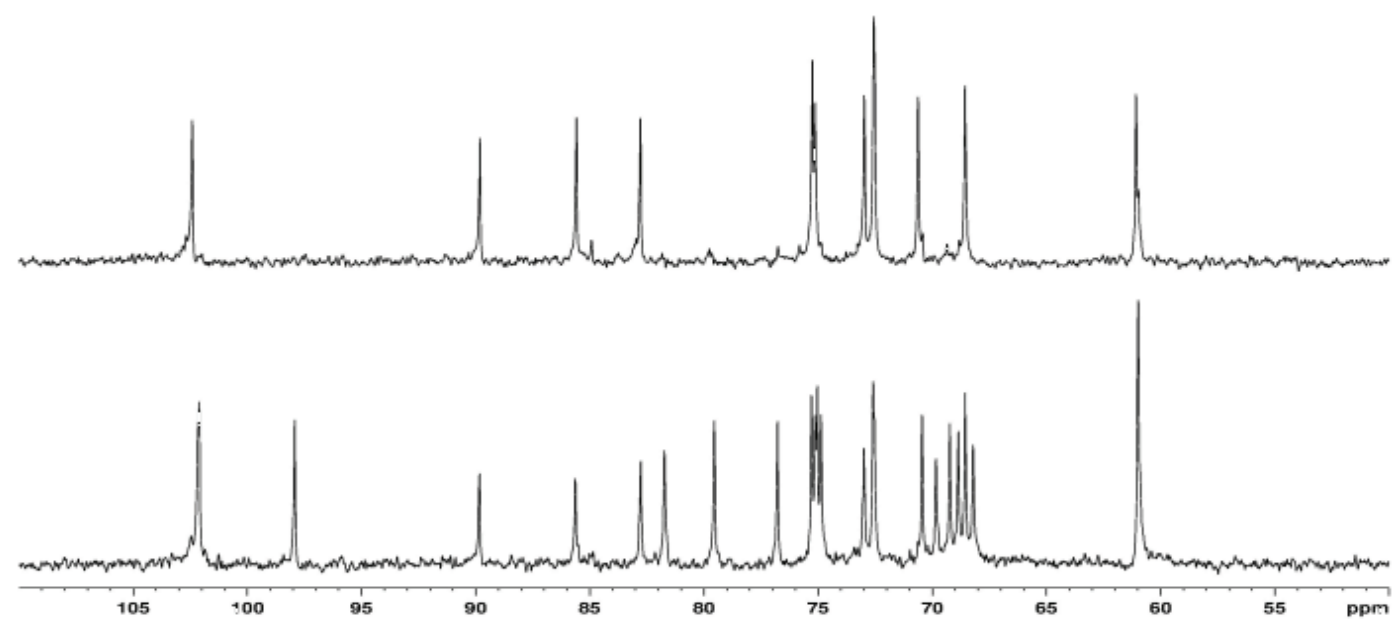

Figure 3. ${ }^{13} \mathrm{C}-\mathrm{NMR}$ spectra of fractions $\mathrm{AA}(\mathrm{a})$ and $\mathrm{AB}(\mathrm{b})$. 
Table 2. ${ }^{1} \mathrm{H}$ - and ${ }^{13} \mathrm{C}-\mathrm{NMR}$ assignments of agaro- and carra-oligosaccharides.

\begin{tabular}{|c|c|c|c|c|c|c|c|c|c|}
\hline \multirow{2}{*}{ Unit } & & \multicolumn{2}{|c|}{ Agarobiose } & \multicolumn{2}{|c|}{ Agarotetraose } & \multicolumn{2}{|c|}{$\kappa$-carrabiose } & \multicolumn{2}{|c|}{$\kappa$-carratetraose } \\
\hline & & ${ }^{1} \mathrm{H}$ & ${ }^{13} \mathrm{C}$ & ${ }^{1} \mathrm{H}$ & ${ }^{13} \mathrm{C}$ & ${ }^{1} \mathrm{H}$ & ${ }^{13} \mathrm{C}$ & ${ }^{1} \mathrm{H}$ & ${ }^{13} \mathrm{C}$ \\
\hline \multirow{7}{*}{$\beta$-D-Galp (ext.) } & 1 & 4.56 & 102.4 & 4.56 & 102.1 & 4.56 & 103.0 & 4.60 & 102.7 \\
\hline & 2 & 3.53 & 70.5 & 3.50 & 70.5 & 3.57 & 70.7 & 3.51 & 70.6 \\
\hline & 3 & 3.66 & 72.5 & 3.65 & 72.6 & 3.82 & 71.4 & 3.80 & 71.6 \\
\hline & 4 & 3.93 & 68.4 & 3.94 & 68.6 & 4.67 & 76.3 & 4.68 & 76.4 \\
\hline & 5 & 3.71 & 75.2 & 3.74 & 75.3 & 3.86 & 74.5 & 3.85 & 74.4 \\
\hline & 6 & 3.78 & 60.9 & 3.77 & 61.0 & 3.82 & 60.9 & 3.80 & 60.8 \\
\hline & $6^{\prime}$ & 3.78 & & 3.77 & & 3.82 & & 3.80 & \\
\hline \multirow{7}{*}{ 3,6-An- $\alpha-\mathrm{Gal} p$ (int.) } & 1 & & & 5.16 & 98.2 & & & 5.10 & 94.2 \\
\hline & 2 & & & 4.14 & 69.3 & & & 4.14 & 69.1 \\
\hline & 3 & & & 4.56 & 79.6 & & & 4.52 & 78.7 \\
\hline & 4 & & & 4.66 & 76.8 & & & 4.61 & 77.8 \\
\hline & 5 & & & 4.57 & 74.9 & & & 4.65 & 76.2 \\
\hline & 6 & & & 4.03 & 68.9 & & & 4.06 & 69.0 \\
\hline & $6^{\prime}$ & & & 4.24 & & & & 4.21 & \\
\hline \multirow{7}{*}{$\beta$-D-Gal $p$ (int.) } & 1 & & & 4.61 & 102.2 & & & 4.59 & 102.2 \\
\hline & 2 & & & 3.66 & 69.9 & & & 3.67 & 69.2 \\
\hline & 3 & & & 3.82 & 81.8 & & & 4.00 & 77.6 \\
\hline & 4 & & & 4.14 & 68.2 & & & 4.84 & 73.2 \\
\hline & 5 & & & 3.74 & 75.1 & & & 3.85 & 74.4 \\
\hline & 6 & & & 3.77 & 61.0 & & & 3.80 & 60.9 \\
\hline & $6^{\prime}$ & & & 3.77 & & & & 3.80 & \\
\hline \multirow{7}{*}{ 3,6-An-Gal (red.) } & 1 & 5.02 & 89.9 & 5.01 & 89.8 & 5.01 & 89.8 & 5.00 & 89.8 \\
\hline & 2 & 3.74 & 72.5 & 3.73 & 72.5 & 3.65 & 72.7 & 3.66 & 72.7 \\
\hline & 3 & 4.08 & 82.8 & 4.07 & 82.8 & 4.09 & 82.3 & 4.09 & 82.4 \\
\hline & 4 & 4.38 & 85.6 & 4.39 & 85.6 & 4.29 & 86.9 & 4.28 & 86.9 \\
\hline & 5 & 4.41 & 75.1 & 4.41 & 75.2 & 4.49 & 75.3 & 4.49 & 75.4 \\
\hline & 6 & 3.86 & 72.8 & 3.86 & 73.0 & 3.86 & 72.7 & 3.84 & 72.8 \\
\hline & $6^{\prime}$ & 3.99 & & 4.00 & & 4.03 & & 4.02 & \\
\hline
\end{tabular}

${ }^{13} \mathrm{C}-\mathrm{NMR}$ analysis of the fraction $\mathrm{AB}$ (Figure $3 \mathrm{~b}$ ) indicated the presence of a tetrasaccharide. The spectrum of agarotetraose 4 (Figure 1, $n=1$ ) has signals in the anomeric region at $98.2 \mathrm{ppm}(\mathrm{C}-1$ of 3,6-anhydro- $\alpha-\mathrm{L}-\mathrm{Gal} p)$ and $102.1 \mathrm{ppm}$ (C-1 of $\beta$-D-Galp), in agreement with previously reported data (Rochas et al., 1994). Two-dimensional NMR experiments were performed to complete the ${ }^{13} \mathrm{C}$ and ${ }^{1} \mathrm{H}$ assignments (Table 2). The structure of agarotetraose was also confirmed by ESIMS analysis. In the positive-ion mode, two molecular ions were observed at $\mathrm{m} / \mathrm{z} 653$ and 671 corresponding to the tetrasaccharide in the aldehyde and hydrated aldehyde forms, $[\mathrm{M}+\mathrm{Na}]^{+}$and $\left[\mathrm{M}+\mathrm{H}_{2} \mathrm{O}+\right.$ $\mathrm{Na}]^{+}$, respectively.

Production of kappa-carrabiose and kappa-carratetraose from kappa-carrageenan
A water-soluble polysaccharide fraction (KWS) was obtained from Kappaphycus alvarezii as previously described (Gonçalves et al., 2005). The monosaccharide composition of KWS showed galactose and 3,6-anhydrogalactose as the principal constituents (Table 1). ${ }^{13} \mathrm{C}$ - and ${ }^{1} \mathrm{H}-\mathrm{NMR}$ analyses presented spectra typical of kappacarrageenan (Van de Velde et al., 2002). In the ${ }^{1} \mathrm{H}-\mathrm{NMR}$ spectrum (not shown), the signal corresponding to $\mathrm{H}-1$ of the 3,6-anhydro- $\alpha$-D-Galp units was observed at $5.10 \mathrm{ppm}$. These results confirmed the presence of kappa-carrageenan as the principal constituent of KWS.

Kappa carrageenan 5 (KWS) was submitted to partial acid hydrolysis (Figure 4 ) for $3 \mathrm{~h}$ to give a mixture of sulfated oligosaccharides. This mixture was purified by gel filtration chromatography on a Sephadex G-25 column to give two principal fractions, KA (21\%) and KB (8\%). 


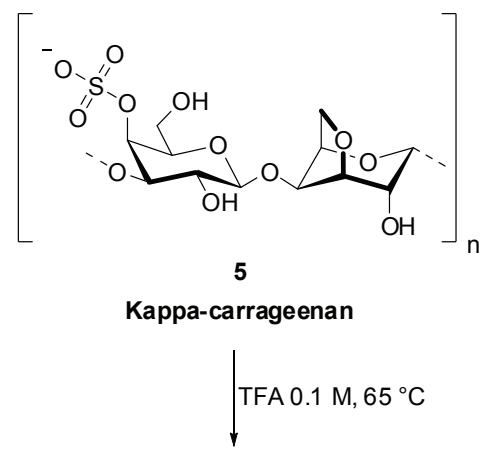

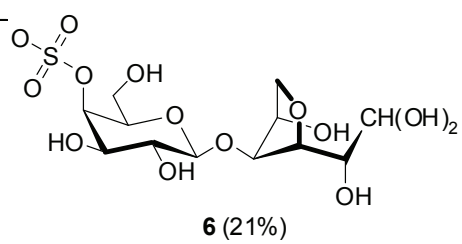

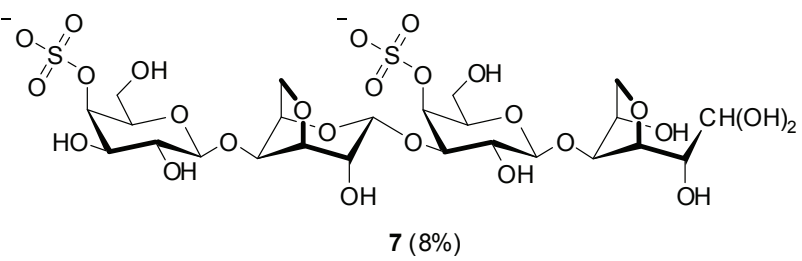

Figure 4. Production of carra-oligosaccharides via partial acid hydrolysis of kappa-carrageenan.

The ${ }^{1} \mathrm{H}-\mathrm{NMR}$ spectrum of KA exhibited a doublet at $5.01 \mathrm{ppm}(J 1,2=6.0 \mathrm{~Hz})$ that was assigned to $\mathrm{H}-1$ of the reducing 3,6-anhydro-galactose units. The ${ }^{13} \mathrm{C}$-NMR spectrum of KA (Figure $5 \mathrm{a}$ ) was attributed to the kappa-carrabiose disaccharide 6 (Figure 4), in agreement with data previously reported (Miller et al., 1982). The resonances at 103.0 and $76.6 \mathrm{ppm}$ were assigned to $\mathrm{C}-1$ and $\mathrm{C}-4$ of the $\beta$-D-Gal $p$-4-sulfate unit, respectively (Table 2). ESIMS analysis in the negativeion mode confirmed the structure of 6 in the fraction KA. Two molecular ions were observed at $\mathrm{m} / \mathrm{z} 403$ and 421, corresponding to the aldehyde and hydrated aldehyde forms $\left[\mathrm{M}-\mathrm{H}^{-}\right.$and $\left[\mathrm{M}-\mathrm{H}+\mathrm{H}_{\curvearrowright} \mathrm{O}^{-}\right.$, respectively.
The ${ }^{13} \mathrm{C}$-NMR spectrum of $\mathrm{KB}$ (Figure $5 \mathrm{~b}$ ) showed three signals in the anomeric region, which were assigned to $\mathrm{C}-1$ of the terminal $\beta$-D-Galp 4-sulfate (102.7 $\mathrm{ppm})$, the internal $\beta$-D-Galp 4-sulfate (102.2 ppm) and the 3,6 -anhydro- $\beta$-D-Galp (94.2 ppm) units. The reducing 3,6anhydro-galactose in the hydrated aldehyde form was also observed via the $\mathrm{C}-1$ signal at $89.8 \mathrm{ppm}$. Complete ${ }^{1} \mathrm{H}$ and ${ }^{13} \mathrm{C}$-NMR assignments (Table 2) and ESIMS analysis confirmed the sulfation at C-4 for both $\beta$-D-Galp units and the presence of kappa-carratetraose 7 (Figure 4) in the fraction KB. All the oligosaccharides isolated presented good stability for months when stored in the freezer.

\section{Agarobiose and agarotetraose production rates determined by HPSEC analysis}

HPLC has emerged as an important tool for carbohydrate analysis (Ascencio et al., 2006; Givry et al., 2007). Facilities such as the lack of a need for derivatization of the sample and the utilization of water as solvent led us to develop a high performance size exclusion chromatographic (HPSEC) method for evaluating the rate of production of agarobiose and agarotetraose from agarose. The partially depolymerized ( $4 \mathrm{~h}$ of hydrolysis) agarose samples, i.e., agarobiose (AA) and agarotetraose $(\mathrm{AB})$, were used to determine the best chromatographic conditions for oligosaccharide separation. Ultra-hydrogel 120,250 and 500 columns were utilized individually or coupled at several temperatures and with different buffers as mobile phases. Good resolution for separation and quantification were found by using an ultra-hydrogel 120 column eluted with ultrapure water at $30{ }^{\circ} \mathrm{C}$ at a flow rate of $0.4 \mathrm{~mL} \cdot \mathrm{min}^{-1}$ (Figure 6 ).

HPSEC analyses of fractions $\mathrm{AA}$ and $\mathrm{AB}$ confirmed the high degree of purity of the oligosaccharides inferred from the ${ }^{1} \mathrm{H}-\mathrm{NMR}$ spectra. Therefore, these oligosaccharides were used as standards to construct calibration curves. Calibration curves were obtained for oligosaccharide concentrations ranging from 0.25 to 2.0 mg. $\mathrm{mL}^{-1}$. The correlation coefficients of the graphs were 0.9999 for agarobiose and 0.9998 for agarotetraose.
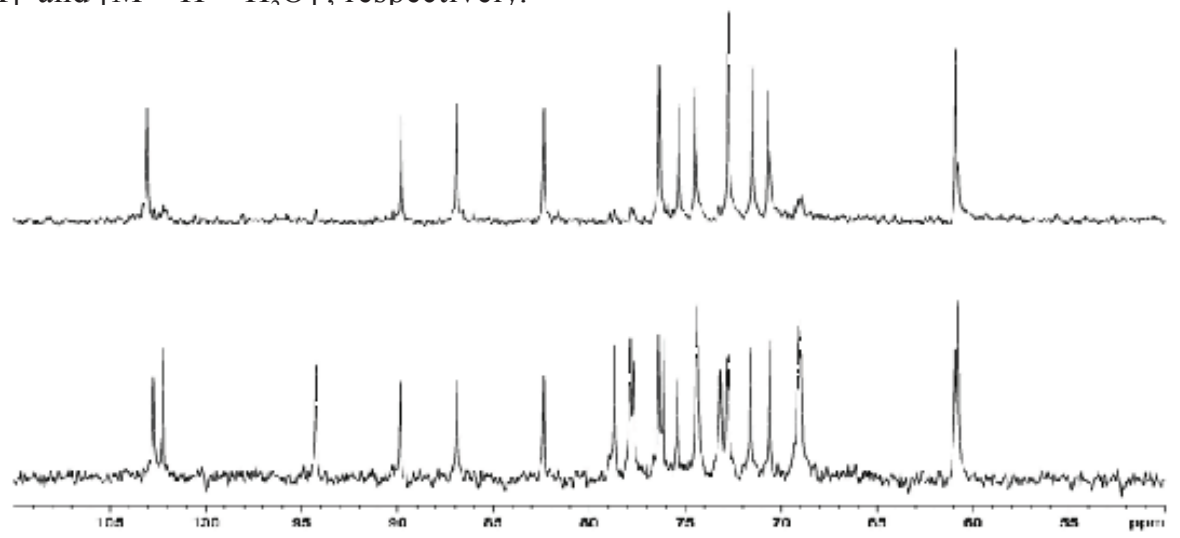

Figure 5. ${ }^{13} \mathrm{C}-\mathrm{NMR}$ spectra of fractions KA (a) and $\mathrm{KB}(\mathrm{b})$. 


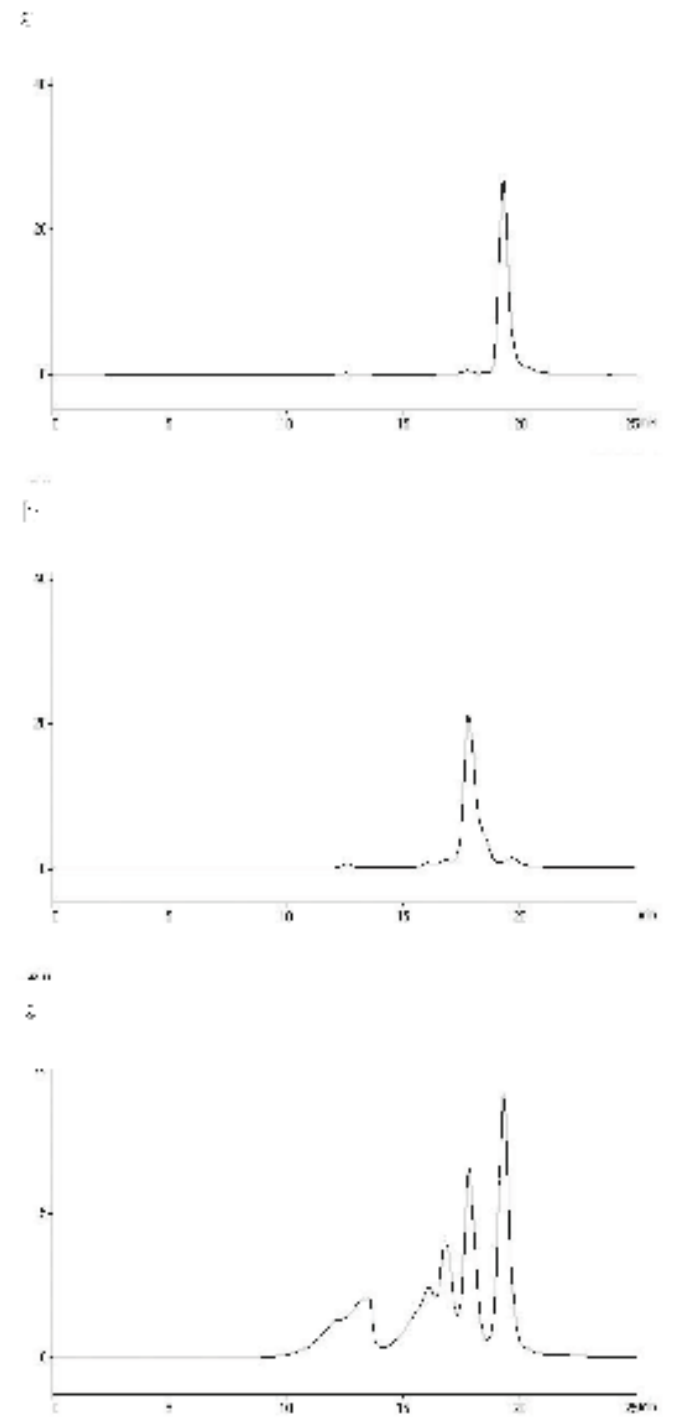

Figure 6. HPLC chromatograms of agarobiose (a), agarotetraose (b) and partially depolymerized agarose (c).

Agarose (sample 1) was submitted to acid hydrolysis for different times and the oligosaccharide mixtures were analyzed by HPSEC. The rates of production of agarobiose and agarotetraose were measured with the assistance of the calibration curves and the results are depicted in Figure 7. The agarobiose content did not exceed that of agarotetraose until four hours of hydrolysis. Although the disaccharide content increased with hydrolysis time, the agarotetraose content remain constant (at aprox. 19\%) between four and eight hours. This suggests that the rates of agarotetraose formation from high molecular mass oligosaccharides and of its hydrolysis to yield agarobiose maintained a constant ratio during these times. At six hours of hydrolysis, about $50 \%$ of the depolymerization products were di- and tetrasaccharides, indicating a rapid hydrolysis of agarose, as expected for a non-sulfated galactan. This rapid rate of hydrolysis can be explained by the lack of substituent groups that might stabilize the galactan 3,6-anhydro-galactosidic bonds.

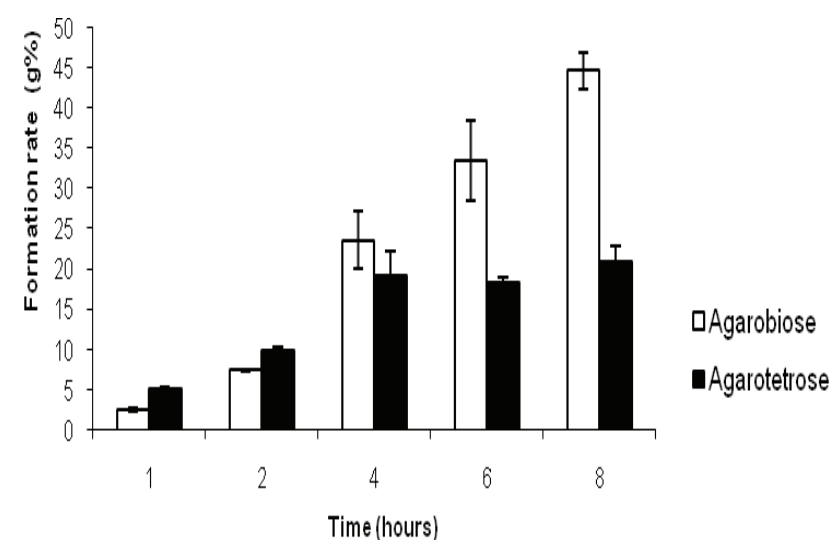

Figure 7. Production of agarobiose ( $\square$ ) and agarotetraose ( $\square$ ) at different hydrolysis times as determined by the HPSEC method.

The preparative gel permeation chromatography of hydrolyzed agarose ( $2 \mathrm{~h}$ of partial hydrolysis) on BioGel P2 provided agarobiose (10\%) and agarotetraose (9\%). These yields are in good agreement with those determined by HPSEC analysis at the same two hours of hydrolysis time.

In conclusion, stable reducing neutral and acidic (sulfated) oligosaccharides with 3,6-anhydro-galactose at the reducing terminal end were obtained by applying partial acid hydrolysis to agarose and kappa-carrageenan. A rapid HPSEC method was developed to estimate the formation of agarobiose and agarotetraose by partial acid hydrolysis from a commercial sample of agarose. Theses methodologies of oligosaccharide production and evaluation show good potential for the production of bioactive galactan oligosaccharides.

\section{Acknowledgements}

This work was supported by the CNPq, PRONEXCARBOIDRATOS (Fund. Araucaria-CNPq) and CAPES. MDN and MED are Research Fellows of the National Research Council of Brazil (CNPq). DRBD is grateful for a doctoral scholarship from the CNPq. FGC acknowledges a graduate scholarship from the $\mathrm{CNPq}$.

\section{References}

Araki C, Hirase S 1953. Studies on the chemical constitution of agar-agar. XV. Exhaustive mercaptolyses of agar-agar. Bull Chem Soc Jap 26: 463-467.

Ascencio SD, Orsato A, França RA, Duarte MER, Noseda MD 2006. Complete ${ }^{1} \mathrm{H}$ and ${ }^{13} \mathrm{C}$ NMR assignment of digeneaside, a low-molecular-mass-carbohydrate produced by red seaweeds. Carbohydr Res 341: 677682. 
Chen H, Yan X, Lin J, Wang F, Xu W 2007. Depolymerized products of $\lambda$-carrageenan as a potent angiogenesis inhibitor. J Agric Food Chem 55: 6910-6917.

Chen HM, Yan XJ 2005. Antioxidant activities of agarooligosaccharides with different degrees of polymerization in cell-based system. Biochim Biophys Acta 1722: 103-111.

Chen HM, Zheng L, Lin W, Yan XJ 2004. Product monitoring and quantitation of oligosaccharides composition in agar hydrolysates by precolumn labeling HPLC. Talanta 64: 773-777.

Ciancia M, Sato Y, Nonami H, Cerezo AS, Erra-Balsells R, Matulewicz MC 2005. Autohydrolysis of a partially cyclized $\mathrm{mu} / \mathrm{nu}$-carrageenan and structural elucidation of the oligosaccharides by chemical analysis, NMR spectroscopy and UV-MALDI mass spectrometry. Arkivoc 12: 319-331.

Craigie JS 1990. Cell walls. In Cole KM, Sheath RG(Eds) Biology of the red algae, New York: Cambridge University Press, p 221-257.

Dubois M, Gilles KA, Hamilton JK, Rebers PA, Smith F 1956. Colorimetric method for determination of sugars and related substances. Anal Chem 28: 350-356.

Ducatti DRB, Massi A, Noseda MD, Duarte MER, Dondoni A 2009. Production of carbohydrate building blocks from red seaweed polysaccharides. Efficient conversion of galactans into C-glycosyl aldehydes. Org Biomol Chem 7: 576-588.

Enoki T, Okuda S, Kudo Y, Takashima F, Sagawa H, Kato I 2010. Oligosaccharides from agar inhibit pro-inflammatory mediator release by inducing heme oxigenase 1 . Biosci Biotechnol Biochem 74: 766-770.

Enoki T, Sagawa H, Sakai T, Oyashiki H, Sakakibara H, Ochiai K, Kato I 2007. Agarobiose-containing composition. U.S. Patent 7,217,817.

Fatema MK, Nonami H, Ducatti DRB, Gonçalves AG, Duarte MER, Noseda MD, Cerezo AS, Erra-Balsells R, Matulewicz MC 2010. Matrix-assisted laser desorption/ ionization time offlight(MALDI-TOF) mass spectrometry analysis of oligosaccharides and oligosaccharide alditols obtained by hydrolysis of agaroses and carrageenans, two important types of red seaweed polysaccharides. Carbohydr Res 345: 275-283

Givry S, Bliard C, Duchiron F 2007. Selective ketopentose analysis in concentrate carbohydrate syrups by HPLC. Carbohydr Res 342: 859-864.

Gonçalves AG, Ducatti DRB, Duarte MER, Noseda MD 2002. Sulfated and pyruvylated disaccharide alditols obtained from a red seaweed galactan: ESIMS and NMR approaches. Carbohydr Res 337: 2443-2453

Gonçalves AG, Ducatti DRB, Grindley TB, Duarte MER, Noseda MD 2010. ESI-MS differential fragmentation of positional isomers of sulfated oligosaccharides derived from carrageenans and agarans. J Am Soc Mass Spectrom 21: 1404-1416.

Gonçalves AG, Ducatti DRB, Paranha RG, Duarte MER, Noseda MD 2005. Positional isomers of sulfated oligosaccharides obtained from agarans and carrageenans: preparation and capillary electrophoresis separation. Carbohydr Res 340: 2123-2134.

Guibet M, Kervarec N, Genicot S, Chevolot Y, Helbert W 2006.
Complete assignment of ${ }^{1} \mathrm{H}$ and ${ }^{13} \mathrm{C}$ NMR spectra of Gigartina skottsbergii $\lambda$-carrageenan using carrabiose oligosaccharides prepared by enzymatic hydrolysis. Carbohydr Res 341: 1859-1869.

Haijin M, Xiaolu J, Huashi GJ 2003. A $\kappa$-carrageenan derived oligosaccharide prepared by enzymatic degradation containing anti-tumor activity. J Appl Phycol 15: 297303

Kazlowski B, Pan CL, Ko YT 2008. Separation and quantification of neoagaro- and agaro-oligosaccharide products generated from agarose digestion by $\beta$-agarase and $\mathrm{HCl}$ in liquid chromatography systems. Carbohydr Res 343: 2443-2450.

Kobayashi E, Li TP, Enoki T, Tominaga T, Sagawa H, Kato I 2003. Remedies. U.S. Patent 6,518,302.

Mazumder S, Ghosal PK, Pujol CA, Carlucci MJ, Damonte $\mathrm{EB}$, Ray B 2002. Isolation, chemical investigation and antiviral activity of polysaccharides from Gracilaria corticata (Gracilariaceae, Rhodophyta). Int $J$ Biol Macromol 31: 87-95.

Miller IJ, Wong H, Newman RH 1982. A 13C n.m.r. study of some disaccharides from algal polysaccharides. Aust $J$ Chem 35: 853-856

O'Neill AN 1955. 3,6-Anhydro-D-galactose as a constituent of к-carrageenin. J Am Chem Soc 77: 2837-2839.

Painter TJ 1983. Algal Polysaccharides. In Aspinall GO (Ed.) The polysaccharides. vol. 2, New York: Academic Press, p. 195-285.

Penman A, Rees DA 1973. Carrageenans. Part XI. Mild oxidative hydrolysis of $\kappa$ and 1 -carrageenans and the characterisation of oligosaccharide sulphates. $J$ Chem Soc 19: 2191-2196.

Rochas C, Potin P, Kloareg B 1994. NMR spectroscopic investigation of agarose oligomers produced by an $\alpha$-agarase. Carbohydr Res 253: 69-77.

Stevenson T, Furneaux R 1991. Chemical methods for the analysis of sulphated galactans from red algae. Carbohydr Res 210: 277-298.

Usov AI, Elashvili MY 1991. Polysaccharides of algae 44. Investigation of sulfated galactan from Laurencia nipponica Yamada (Rhodophyta, Rhodomelaceae), using partial reductive hydrolysis. Bot Mar 34: 553-560.

Van de Velde F, Knutsen SH, Usov AI, Rollema HS, Cerezo AS 2002. ${ }^{1} \mathrm{H}$ and ${ }^{13} \mathrm{C}$ high resolution NMR spectroscopy of carrageenans: application in research and industry. Trends Food Sci Technol 13: 73-92.

Yang B, Yu G, Zhao X, Jiao G, Ren S, Chai W 2009. Mechanism of mild acid hydrolysis of galactan polysaccharides with highly ordered disaccharide repeats leading to a complete series of exclusively odd-numbered oligosaccharides. FEBS J 276: 2125-2137.

Young KS, Bhattacharjee SS, Yaphe W 1978. Enzymic cleavage of the $\alpha$-linkages in agarose, to yield agarooligosaccharides. Carbohydr Res 66: 207-212.

Yu G, Guan H, Ioanoviciu AS, Sikkander AS, Thanawiroon C, Tobacman JK, Toida T, Linhardt RJ 2002. Structural studies on $\kappa$-carrageenan derived oligosaccharides. Carbohydr Res 337: 433-440.

Zibetti RGM, Duarte MER, Noseda MD, Colodi FG, Ducatti DRB, Ferreira LG, Cardoso MA, Cerezo AS 2009. Galactans from Cryptonemia species. Part II: Studies 
on the system of galactans of Cryptonemia seminervis (Halymeniales) and on the structure of major fractions. Carbohydr Res 344: 2364-2374.

Zibetti RGM, Noseda MD, Cerezo AS, Duarte MER 2005. The system of galactans from Cryptonemia crenulata (Halymeniaceae, Halymeniales) and the structure of two major fractions. Kinetic studies on the alkaline cyclization of the unusual diad G2S-D(L)6S. Carbohydr Res 340: 711-722.

\section{*Correspondence}

Miguel D. Noseda

Departamento de Bioquímica e Biologia Molecular, Universidade Federal do Paraná

Centro Politécnico, Caixa Postal 19046, 81-531-980 CuritibaPR, Brazil

mdn@ufpr.br

Tel.: +55 4133611663

Fax: +55 4132662042 